ROCZNIKI FILOZOFICZNE

Tom LXVIII, numer $4-2020$

DOI: https://dx.doi.org/10.18290/rf20684-11

PIOTR KULICKI

\title{
ADVANCES IN PHILOSOPHICAL LOGIC: EDITORIAL TO THE THEMATIC SECTION
}

In the review of habilitation of Zdzisław Dywan, an emeritus professor of the John Paul II Catholic University of Lublin (KUL in short), who passed away 18.05.2020 at the age of 69, Ryszard Wójcicki wrote back in 1986: "On the Polish logic map Lublin is little known. Significant works from there published in the recent years are the works of Dr. Dywan." By now the situation has changed. A noticeable group of researchers is working at KUL on different aspects of philosophical logic. Most of them were educated at KUL, being students of Stanisław Kiczuk, another emeritus professor, Zdzisław Dywan and their students. They are working in two departments within the Institute of Philosophy, in the Department of Logic: Marcin Tkaczyk (chair), Marcin Czakon, Bożena Czernecka-Rej, Anna Karczewska, Anna Kozanecka-Dymek, Marek Lechniak, and in the Department of the Foundations of Computer Science: Paweł Garbacz (chair), Fengkui Ju, Piotr Kulicki, Xin Sun, and Robert Trypuz.

Organizing conferences is one of the factors influencing the visibility and impact of the group. The highlight of this kind of activity in the recent years was Trends in Logic XVII conference from 2017 titled Traditional and new perspectives on deontic logic and agency modeling co-organized by the Faculty of Philosophy of KUL and Studia Logica. Chinese-Polish Workshop on Applied Logic is another cycle of events of that kind co-organized by the Faculty of Philosophy of KUL. Three editions already took place: first at the Beijing Normal University in December 2017, second at the Nicolaus Copernicus University in Torun in September 2018 and third at Zhejiang Uni-

Prof. Dr. Habil. Piotr Kulicki, the John Paul II Catholic University of Lublin, Faculty of Philosophy, Institute of Philosophy, Department of Fundamentals of Computer Science; address for correspondence: Al. Racławickie 14, 20-950 Lublin; e-mail: piotr.kulicki@kul.pl; ORCID: 00000001-5413-3886. 
versity in Hangzhou in September 2019. The forth workshop, planned for August 2020 in Lublin, is postponed due to Covid-19 epidemic situation to 2021.

However, the oldest conference devoted to logic that regularly take place at KUL is the yearly Jesienna Konferencja Logiki (Autumn Conference of Logic). The fist one that took place in 2009 was organized by Anna Kozanecka-Dymek, the folowing ones were lead by Marek Lechniak. Each year the conference gathered researchers from the major Polish scientific institutions around a different main topic. The topics so far included applications of modal logic, mutual relations between logic and philosophy, logic in science, logic in theology, logic and norms, logic and cognitive science, logic and language, logic and modality. The $11^{\text {th }}$ edition of the conference in 2019 entitled Advances in philosophical logic was the first international one. Keynote speakers of the conference were Valentin Goranko (Stockholm University), Ondrej Majer (Czech Academy of Science, Prague) and Antonino Rotolo (University of Bologna). The conference was supported financially by "Regional Initiative of Excellence" 2019-2022, project no. 028/RID/2018/19.

The present collection of articles constituting a part of this issue of Roczniki Filozoficzne (Annals of Philosophy) is related to the aforementioned conference activity, especially to the last Autumn Conference of Logic. Some of the papers are the final versions of works presented at the conferences, all of them address problems discussed there.

The first two articles belong to history and philosophy of logic. The article "The inference pattern Mou in Mohist logic" by Fenrong Liu and Zhiqiang Sun investigates detailed issues concerning ancient Chinese Mohist logic. A pattern of reasoning called Mou is analyzed from both linguistic and logical point of view. I hope that such a presentation of the achievements of ancient Chinese logic to the Western readers will inspire further research among others on comparison of these achievements to the logical works of Aristotle, who was contemporary to the Mohist school. The article "On four types of argumentation for classical logic" by Bożena Czernecka-Rej refers to the distinguished role of classical logic among other logical systems. The author discuses different types of argumentation supporting the claim that classical two-valued logic is the right logic or at least that it constitutes a proper point of reference for any further research.

Another two articles attempt to tackle problems vivid in contemporary philosophical logic. The article "Knowability as de re modality" by Tomasz Jarmużek, Rafał Palczewski and Krzysztof Krawczyk concerns the notion of knowability. The authors propose their way to avoid Fitch paradox. Their 
solution, unlike other solutions of the problem, is based on the de re interpretation of knowability. The article "Non-classical probabilities for decision making in situations of uncertainty" by Ondrej Majer, Dominik Klein and Soroush Rafiee Rad, discusses two non-classical approaches to probabilistic reasoning. One of them is Dempster-Shafer theory and the other is nonstandard probability theory based on Belnap-Dunn logic. The authors compare the two approaches with a special attention put on various dynamical rules of the two frameworks seen as generalizations of classic Bayes' conditioning.

The last two papers concern positional logic that was developed and studied in recent years mainly by researchers from KUL and the Chair of Logic of Nicolus Copernicus University in Torun. The article "On some language extension of logic MR. A semantic and tableaux approach" by Aleksander Parol and Tomasz Jarmużek discuses formal aspects of a certain positional logic allowing for the use of multiple labeling of propositions. The logic is claimed to be useful for reasoning within social ontology. As the title of the paper states a formal semantic and a proof system based on tableaux method is presented. The article "Set-theoretic semantics for many-valued positional calculi" by Anna Karczewska concerns a class of positional calculi called many-valued positional calculi, as they can be defined using many-valued matrices. The author introduces an alternative, set-theoretic semantics for that calculi. 